ПСИХОЛОГИЯ ПОТРЕБИТЕЛЕЙ КАК ОБЬЕКТ МАРКЕТИНГОВОГО АНАЛИЗА

DOI: $10.31618 /$ ESU.2413-9335.2020.4.70.554

Зеленина T.P.

Доцент кафедрь

Менеджмента РосНОУ

к.соииолог.наук

\title{
CONSUMER PSYCHOLOGY AS AN OBJECT OF MARKETING ANALYSIS
}

T.R. Zelenina

\section{АННОТАЦИЯ}

В статье рассматриваются особенности психологии потребителей разных поколений и ценности, лежащие в основе их поведения.

\section{ABSTRACT}

The article examines the features of consumer psychology of different generations and the values that underlie their behavior.

Ключевые слова: поколенческий подход, потребительское поведение, психические процессы, ценности.

Keywords: generational approach, consumer behavior, mental processes, values.

Значительные

трансформации

потребительских запросов в последнее десятилетие привело к возрождению исследовательского интереса к психологическим аспектам потребительского поведения. Традиционный маркетинг побуждает производителей выявлять человеческие нужды и создать привлекательные объекты для их удовлетворения. Предполагалось, что все потребители руководствуются своими сугубо утилитарными соображениями и приобретают, прежде всего, необходимые им услуги и товары. Долгое время, практически на протяжении всего XX столетия, производители и продавцы направляли свои усилия на создание и продвижение привлекательных по цене и полезных для потребителей товаров. Сегодня исследователи маркетинга начинают осознавать, что запросы современного потребителя существенно отличаются от запросов их предшественников.

Систематические исследования потребительского поведения появились в конце 1950-х - начале 1960-х гг., тогда же возникла отрасль научного знания и учебная дисциплина «Поведение потребителя». Все научные изыскания второй половины прошедшего столетия так или иначе касались анализа психических процессов потребителя. Выявлялись мотивы, стимулы, а также различные типы покупательского поведения $[1$, c. 38$]$

Обобщая данные исследований специалистов в области маркетинга потребительское поведение можно определить как совокупность действий, связанных с поиском, выбором, оплатой, использованием товара, а также с оценкой потребителем правильности сделанного выбора. [2, c.123]

Согласно теоретическим основам психологии, в основе потребительского поведения лежат:

- личностные мотивы индивида;

- стремление к удовлетворению имеющихся потребностей;
- жажда исполнения желаний.

Личностные особенности потребителя включают в себя его пол, возраст, гендерную принадлежность, привычки, настроение, нравственность и пр. Некоторые ученые относят к ним коммуникативные, мотивационно-волевые факторы, а также соотношение рациональных и эмоциональных черт (элементов) в профиле личности. Психология потребительского поведения говорит о том, что мотивы человека при покупке им продукта с целью удовлетворения потребностей предельно прозрачны, ясны и понятны. Намного сложнее их выявить и оценить в том случае, если потребителем руководит какоелибо другое желание.

Потребностям и их удовлетворению отводится основополагающая роль в формировании поведения потребителей. Под потребностями следует понимать осознанную нужду, которую человек испытывает в связи с желанием и необходимостью обеспечения нормальной жизнедеятельности. Все потребности требуют своего удовлетворения по определенному алгоритму.

Жажда исполнения желаний - ещё один фактор, формирующий поведения потребителя. Под желанием следует понимать влечение, стремление к осуществлению чего-нибудь, обладанию чем-нибудь [3, с.191]. То есть, по сути, желание - это материализация потребностей. Это потребность, которая принимает конкретную форму в соответствии с социально-культурным укладом и представлениями человека.

Согласно традиционной точке зрения, потребности - это то, без чего человек не может обойтись, а желания - то, без чего он обойтись может, иными словами, его прихоть, или «роскошь». Исследователи потребительского поведения утверждают, что «в современном мире практически все покупки, даже считающиеся излишними, отражают действительные 
потребности некоторой части покупателей, поскольку им нужны именно эти вещи и на меньшее они не согласны» [4, с. 27].

Для понимания поведения покупателя в новой экономической ситуации маркетологи должны расширить свои представления о психологических основах потребительских мотивов. Схемы и правила решения потребителей о совершении покупок претерпели значительные изменения: желания потребителей превратились в потребности, логического объяснения которым маркетологи дать не в состоянии. Покупатели приобретают вещи не очень нужные, да ещё и по завышенным ценам. Сюда можно отнести покупки брендовой одежды, автомобилей, бытовой электроники, смартфонов. Многие покупки совершаются с помощью потребительских кредитов, которые выплачиваются потом длительное время. Зачастую такие решения трактуются как приобретение под влиянием момента, т.е. акт импульсивной покупки, однако это очень узкий взгляд на проблему. Следует отметить, что в этих случаях покупатели сами затрудняются назвать причины подобного поведения.

Задача современного исследователя потребительского поведения заключается в выявлении мотивов, глубинных психологических потребностей и желаний современного покупателя. Среди новых общих тенденций, характеризующих поведение современного покупателя нужно отметить следующие:

- стремление потребителей всегда оставаться на связи и иметь доступ к различным интернетсервисам в любое время суток. Потенциальные клиенты могут выйти в интернет даже с часов, поэтому важно, чтобы сайт был готов к любому устройству, экрану и даже формату запросов. Голосовой поиск становится все популярнее - по прогнозу Comscore 50\% всех запросов к 2020 году будут именно в этом формате.

- эмоциональная вовлеченность. Сервисы, которые гарантируют яркие эмоции, набирают популярность. Например, сервис OneTwoTrip предлагает организовать путешествие в неожиданное место (в стоимость входят билеты и проживание), сообщив о пункте назначения за 2 суток или уже на пути в аэропорт. Весьма популярной становится геймификация возможность дать взрослым почувствовать себя детьми через квесты, игры, изучение материала в игровой форме и т. д., персонализация - настройка рекомендательной системы или ручная подборка спецпредложений;

стремление все контролировать и организовывать. Согласно исследованиям психологов, люди, живущие в условиях нестабильной экономики, стараются максимально контролировать все вокруг себя. Это придает им уверенность в завтрашнем дне. Пользователи стремятся контролировать все и максимально эффективно организовывать свой день: отключают ненужные уведомления, заказывают еду из супермаркета на дом, включают пылесос со смартфона, пока находятся на работе.
- рационализация потребления. Несмотря на то, что экономическая ситуация в области потребления стабилизируется (по данным Федеральной службы государственной статистики потребительские расходы во втором квартале 2019 года повысились на $6 \%$ по сравнению со вторым кварталом 2018 года [5]), пользователи попрежнему стараются контролировать свои расходы. Они все чаще ищут акции и спецпредложения, пользуются коллективными покупками и семейными подписками на сервисы.

- индивидуализация потребления. В условиях многообразия товаров и услуг потребитель предъявляет всё более нестандартные требования как к самим товарам и услугам, так и к процессу их продажи и оказания. Наблюдается явное предпочтение небольших брендов массовым. Появилась мода на крафтовые продукты. Этим прилагательным называют продукты, сделанные не на заводе, а в мастерской, маленькими партиями по индивидуальным рецептам. Мода на крафт видна во всем: от маленьких пивоварен до частных архитектурных бюро. Пользователи ищут не традиционное маркетинговое общение, а индивидуальный подход и влияние к деталям. Но тут появляется новая проблема - маленьким брендам сложнее заявить о себе. Чаще всего работает сарафанное радио, и это плюс информация от других пользователей вызывает больше доверия [6].

Данные тенденции можно проследить в поведении представителей всех поколений потребителей, однако, нельзя не отметить и некоторые различия и особенности, которые не могут не заинтересовать деятелей в сфере маркетинга и продаж. Поколенческий подход к построению моделей потребления различных возрастных групп населения позволяет исследователям маркетинга описать потребительскую практику современных россиян. Данный подход увязывает анализ среды формирования ценностей поколений с их нуждами и потребностями, a, следовательно, дает специалистам-маркетологам инструмент для формирования эффективных маркетинговых стратегий.

Согласно этой теории, приблизительно каждые 20 лет на свет появляется новое поколение людей, система ценностей которых кардинально отличается от системы ценностей их родителей, бабушек или дедушек. Формирование системы ценностей представителя каждого нового поколения фактически заканчивается к 11-15 годам, после чего она только дополняется и укрепляется. Уже в этом возрасте можно заметить первые отличия: отношение к другим людям, деньгам, материальным и духовным благам, стиль потребления и поведения в целом. Исчисление и описание «поколений» начинается с конца XIX века. Каждое из поколений имеет свои уникальные ценности, которые формировались под влиянием множества факторов. Деятельность представителей каждого поколения провоцировала создание новых условий, которые, в свою очередь, начинали влиять 


\section{на формирование системы ценностей последующего поколения [7].}

Наибольший интерес для исследователей представляет, на наш взгляд, три последних поколения, так как являются наиболее платежеспособными и активными потребителями товаров и услуг. Это поколения X, Y, Z - самые изученные поколения в маркетинге.

Каковы же условия формирования и психологические основы их потребительских предпочтений?

Поколение «Х» («неизвестное» поколение, поколение «с ключом на шее») - люди, рожденные в период с 1963 по 1983. События, повлиявшие на формирование их ценностей: продолжение «холодной войны», перестройка, СПИД, наркотики, войны в Афганистане и Чечне. Их система ценностей включает: способность к изменениям, обдумывание своего выбора, высокая информированность, техническая грамотность и качественное образование, стремление учиться на протяжении всей жизни, поиск острых эмоций, индивидуализм и прагматизм, надежда на самого себя, стремление к лидерству, признание равноправия полов, прочная уверенность в себе, поиски благополучия, трудолюбие, честность и дружелюбие.

Покупательская социализация представителей поколения X происходила в условиях появления новых форматов магазинов: супермаркетов и гипермаркетов, что, безусловно, сильно повлияло на потребительские стандарты поколения. Появление новых форматов магазинов «возле дома» продиктовано привычками представителей поколения X совершать покупки товаров первой необходимости недалеко от места проживания. Сетевые ритейлеры обратили внимание на то, что данная когорта покупателей весьма ценит свое удобство, готова тратить на это деньги и предпочитает приобретать много разных товаров хорошего качества в одном месте, делать это очень быстро с экономией времени. Именно для таких покупателей сетевые супермаркеты и гипермаркеты распахнули двери с предложениями индивидуальных товаров и услуг.

Для поколения «Х» важно подчеркнуть свою индивидуальность и уникальность. На стадии принятия покупательского решения, при оценке вариантов выбора товаров это поколение склонно к самостоятельности. Для него характерно принятие решения о покупке без учета требований референтных групп. Покупательское поведение этого поколения может быть выражено словами: «добавь своей индивидуальности, создай такую вещь, которой не будет больше ни у кого». Взвешивая варианты будущей покупки товаров, они ищут ответ на свой вопрос: что в этом товаре или услуге есть именно «моего», для меня. Признак благополучия для этого поколения - это новый интересный и нужный продукт. Они готовы долго пробовать, тестировать и изучать новые товары.

Компания IKEA чутко уловила эту тенденцию и предложила идею индивидуальности в поиске оборудования квартир и дачных домов. Покупатель IKEA имеет возможность воспроизвести собственную концепцию интерьера и найти свой индивидуальный стиль жилой обстановки $[8$, с. 8$]$.

Именно это поколение стало пионером освоения новых социокультурных пространств в виде торгово-развлекательных центров, где возможно не только купить товары, но и приобщиться к новым способам проведения досуга в виде рассматривания витрин, посещения кафе, кинотеатров и иных развлекательных площадок. К новым социокультурным пространствам относятся также и рестораны быстрого питания, прежде всего «Макдональдс» [9, с. 52].

По мнению исследователей, именно представители поколение «Х» является основными потребителями фаст-фудов. Во многом это объясняется тем, что они рационально относятся к использованию своего свободного времени. Представители этого поколения, которые родились и взрослели в России, еще помнят времена тотального дефицита и бесконечное стояние в очередях, поэтому бережно относятся к своему свободному времени и организации досуга. Концепция тайм-менеджмента была разработана и внедрена в повседневную практику именно представителями этого поколения. Их главный лозунг: «время - деньги!» И именно для них производители разработали массу товаров и услуг, которые призваны экономить время потребителей, которые готовы потратить лишние деньги, но не потратят лишнее время. Именно этим объясняется то, что поход к врачу совершается ими только в случае крайней необходимости, причем не в местную поликлинику, а в платный медицинский центр.

При этом поколение «Х» является активными потребителями лекарственных препаратов, которые мгновенно снимают симптомы боли и неудобства. Им важно быть постоянно работоспособными.

Для поколения «Х» одной из важнейших ценностей являются знания и образование. Это они имеют по два и три образования, закончили МВА, получили степени в западных университетах и колледжах. Они не жалеют деньги и на образование своих детей, полагая, что это инвестиции в культурный капитал личности своего ребенка.

Многие социальные сети были разработаны представителями именно этой возрастной общности. Представители поколения X нуждаются в социальных контактах с теми людьми, которые связаны с ними общими переживаниями, событиями детства, учебы. Они стремятся делиться своими мыслями, идеями, мнениями с другими людьми. Анализ социальных сетей показал, что данная группа пользователей наиболее активна и достаточно многочисленна.

Следующее поколение - миллениалы, «поколение NEXT», «поколение Y» - всё это названия большой группы населения, родившейся в период после 1984 и до 2000 года. гг. Люди в возрасте 20-35 лет постепенно становятся основной экономической силой и как работники, и как потребители товаров. В нашей стране «игреки» в дефиците из-за демографического провала 90-х, к ним можно отнести около 30 млн человек или около 
$21 \%$ населения. Это самая много численная и платежеспособная группа потребителей, поэтому анализ ее покупательских мотивов и предпочтений весьма важен для маркетологов и продавцов. Представители данной группы обладают уникальным набором приоритетов и ожиданий, серьезно отличающимся от тех, что знакомы предыдущим поколениям.

Представители поколения $\mathrm{Y}$ привыкли пользоваться услугами разнообразных интернетмагазинов. Они с удовольствием исследуют десятки магазинов в погоне за действительно уникальной вещью. Эксперты отмечают, что предпочтения миллениалов сместились в сторону непостоянного и нематериального - интересов и эмоциональных впечатлений. Современные потребители миллениалы уже отходят от общества потребления и уверенно делают выбор в сторону сферы интересного досуга и услуг.

Одно из самых многочисленных поколений в истории человечества готово вступить в очередной жизненный этап - этап растрат. Благодаря своему уникальному жизненному опыту миллениалы могут изменить экономику, изменив привычные маркетологу покупки и продажи, заставив компании задуматься над долгосрочными стратегиями продвижения.

Особенности поведения миллениалов в процессе совершения покупок:

- в процессе совершения покупки ожидают скорость, простоту, эффективность и удобство;

- редко совершают спонтанные покупки. Прежде чем сделать покупку изучают отзывы друзей и других покупателей;

- ценят бренды со страницами в соцсетях и вебсайтами;

- отдают предпочтение брендам, поддерживающим общественные и экологические движения.

К основным покупательским характеристикам миллениалов можно отнести.

- использование оценок и обзоров как основного критерия при покупке товаров онлайн $(50 \%)$

- предпочтение шоуруминга, т.е. просмотра товара в магазине с его последующей покупкой онлайн $(32 \%)$;

- использование вебруминга, т.е. просмотра товара онлайн с последующей покупкой в магазине $(46 \%)$; $(73 \%)$

- совершение покупок через свои смартфоны

- изучение всех характеристик товара до совершения покупки (72\%);

поиск качественного обслуживания, непрерывного на всех этапах покупки по всем каналам связи с продавцом (68\%).

При выборе продавца представители поколения $\mathrm{Z}$ наиболее значимыми считают лучшую цену (56\%), мнение друзей и семьи $(35 \%)$, гуманитарные ценности (10\%).

На их решение о покупке влияют онлайн обзоры (78\%), друзья и семья $(50 \%)$, реклама $(25 \%)$ [10].
В настоящее время внимание исследователей переключается на новую группу потребителей представителей поколения $\mathrm{Z}$, как одного из самых перспективных сегментов современного потребительского рынка. К поколению Z относятся люди, рожденные после 2000 года. В России молодые люди, родившиеся в период с 2000 по 2019 год, составляют более 21 млн. человек (около 18\% от общей численности населения), большая часть из которых может быть отнесена к поколению Z. Говорить о конкретных чертах потребительского поведения представителей этого поколения ещё рано, так как у них еще мало собственных ресурсов и их покупательная способность пока сравнительно не велика.

В чем же заключаются поведенческие особенности представителей поколения Z, и чем они обусловлены?

Во-первых, высокая компетентность в области электронной техники, что обусловлено влиянием информационно-технологической революции 1990х годов, в условиях которой проходила первичная социализация Z. Поколение $\mathrm{Z}$ стало первым поколением настоящих «цифровых аборигенов», родившихся и выросших в мире компьютеров, сотовых телефонов и смартфонов, широкого использования Интернета с самого раннего возраста, поиска информации в Google, в эпоху социальных сетей, чатов, форумов, сообществ. Именно новые технологии, как считают все исследователи, оказали определяющее влияние на формирование поколение $\mathrm{Z}$.

Во-вторых, особые отношения с членами своей семьи, которая стала важнейшим фактором первичной социализации. Преимущественно родителями поколения $\mathrm{Z}$ являются представители поколения $\mathrm{X}$, которые отступили от жесткого контролирующего стиля, присущего семейным отношениям предыдущих поколений. [11, с. 4]

Родители детей $\mathrm{Z}$ сосредоточили внимание на формировании у своих детей таких качеств, как самостоятельность, адаптивность, стремление к успеху. У поколения Z установились дружеские отношения со своими родителями, оно намного ближе к своим родителям по сравнению с прошлыми поколениями.

В результате подростки поколения Z имеют больше личного пространства, чем их предшественники; они находят ответы на интересующие их проблемы в интернете и более сосредоточены на самих себе. Несмотря на уважительное отношение к своим родителям, они менее от них зависимы. В результате это поколение c подросткового возраста гораздо более самостоятельно и менее управляемо, отличается более высоким уровнем самоуважения.

Известно, что потребительское поведение людей формируется наличием и содержанием потребностей. Какие же наиболее значимые потребности поколения Z выделяют специалисты?

Выделяя наиболее значимые потребности, можно отметить:

- качественно новая потребность в получении информации, требование мгновенного доступа к информации; 
- потребность в общении, причем большинство из них предпочитает коммуникации с людьми не выходя из дома. Поколение $\mathrm{Z}$ комфортно чувствует себя в онлайн-общении;

- потребность в безопасности. Это поколение стремится к стабильности, спокойствию и комфорту;

- с раннего возраста представители поколения Z ориентированы на самореализацию и самоактуализацию, достижение успеха и социального признания;

- потребность в путешествиях, эмоциональное удовлетворение и получение новых ярких и незабываемых впечатлений, потребность в игре. [12, c. 23]

В 2014-2016 годах проведен ряд масштабных исследований особенностей потребительского поведения поколения Z, обусловленных спецификой общей и потребительской социализацией этого поколения, - исследование NRF, «Young\&Younger» агентством MAGRAM Market Research совместно с международным коммуникационным агентством PBN Hill+Knowlton Strategies. В результате были получены данные что, как и по каким каналам продаж совершают покупки представители поколения Z.

Поколение Z (27\%) охотнее покупает новинки, если, конечно, позволяет цена, на нее смотрят $39 \%$ респондентов обоих выборок. Стоит отметить, что $47 \%$ всех опрошенных обращают внимание на инновационные разработки брендов, даже если это маркетинговый ход производителя.

Поколение Z (40\%) больше ориентируется на иностранные бренды, Z выбирают одежду, обувь, электронику и книги. Ү-поколение, в числе прочего, отмечает косметику (21\%), продукты питания (17\%), a Z-поколение предпочитает потратить на спортивные товары (15\%), видеоигры.

Во всех случаях потребители поколения Z изучают товары, которые собираются приобрести 57\%. Каждый второй представитель делает покупки в иностранных онлайн-магазинах (eBay, AliExpress, Asos и др). Российским интернет-магазинам доверяет $41 \%$.

Спонтанные покупки совершают 44\% Zпоколения, поскольку для них посещение торговоразвлекательных центров - это одна из форм проведения досуга. Поэтому они еще предпочитают делать покупки в магазинах. [13, с. 3]

Итак, поколение $\mathrm{Z}$ - хорошо осведомленные и опытные потребители, скептически относятся к рекламе и маркетингу. Они активно используют ресурсы интернета, социальные сети для поиска необходимой информации, сравнивают продукцию разных производителей, выясняют отзывы о конкурентах в реальном времени. Они ищут всегда лучшие предложения на рынке. Любят тратить свои деньги на фирменные и модные товары, соответствующие их образу и стилю жизни, предпочитают искать уникальные и самые современные технологии. При этом ценят дизайн, качество, атмосферу, скорость обслуживания. Важно отметить, что вследствие особенностей своей социализации, отмеченных выше, поколение Z очень нетерпеливые потребители. Они требуют немедленного удовлетворения своих потребностей, мгновенного обслуживания.

Таким образом, поколенческий подход к изучению потребительского поведения дает возможность исследовать глубинные предпочтения потребителей разных поколений и позволяет разрабатывать объекты для удовлетворения их запросов наиболее эффективным способом.

\section{Литература}

1. Блэкуэлл, Р. Поведение потребителей / Р. Блэкуэлл, П. Миниард, Дж. Энджел. СПб: Питер; 2014. - 944 c.

2. Дементьева И.Н. теоретикометодологические подходы к изучению потребительского поведения. // Проблемы развития территории. - 2018. - Вып. 1 (93). - С.122-132

3. Ожегов, С.И. Толковый словарь русского языка. Около $100 \quad 000$ слов, терминов и фразеологических выражений - М.: Мир и образование -2017. -1376 с.

4. Пулер, Джим. Почему мы покупаем. Мотивация и стратегия продаж. - М.: ЗАО «ОлимпБизнес», 2006. - 272 с.

5. Федеральная служба государственной статистики. Доходы, расходы и потребление домашних хозяйств. [Электронный ресурс]. Режим доступа: http://old.gks.ru/wps/wcm/connect/rosstat_main/rossta $\mathrm{t} / \mathrm{ru} / \mathrm{statistics} /$ publications/catalog/doc_114009681281 2

6. Тренды потребительского поведения 2019. [Электронный ресурс]. - Режим доступа: https://www.retail.ru/news/trendy-potrebitelskogopovedeniya-2019/.

7. Поколение X: почему стоит брать на работу людей старше 40 лет. [Электронный ресурс]. Режим доступа: https://www.hrdirector.ru/pokolenie-x

8. Шевченко, Д.А. Исследование потребительского поведения крупных сегментов рынка в России: поколенческий подход. // Практический маркетинг. - 2013, Вып. 4, с. 4-13.

9. Томбу, Д.В. Социология рекламной деятельности: учебное пособие. - М.: ИД «ФОРУМ»: ИФРА-М, 2009 - 240 с.

10. Миллениалы: покупательское поведение. [Электронный ресурс]. - Режим доступа: https://rusability.ru/infographics/millenialypokupatelskoe-povedenie-infografika/

11. Малетин С.C., Особенности потребительского поведения поколения Z/ Малетин С.C.// предпринимательство» - 2017. - № 21. С. 23-24.

12. Шамис Е., Никонов Е. Теория поколений. Необыкновенный Икс. - М.: Синергия, 2016.

13. Ирина Милош, Исследование: Сбербанк изучил поколение $\mathrm{Z}$ Доклад банка посвящен «центениалам». Sostav. [Электронный ресурс]. URL: http://www.sostav.ru/publication/issledovaniesberbank-izuchil-pokolenie-z-25885.html. 